\title{
Biomimetic monolayer films of Monogalactosyldiacylglycerol incorporating Ubiquinone
}

\author{
Javier Hoyo $^{\text {a }}$, Juan Torrent-Burgués ${ }^{\text {a,b, }}$, Ester Guaus ${ }^{a}$ \\ ${ }^{a}$ Department of Chemical Engineering, Universitat Politècnica de Catalunya, Colom 1, 08222 \\ Terrassa (Barcelona), Spain \\ ${ }^{\mathrm{b}}$ Institut de Bioenginyeria de Catalunya (IBEC), Baldiri Reixac 10, 08028 Barcelona, Spain \\ *Corresponding autor: Department of Chemical Engineering, Universitat Politècnica de \\ Catalunya, Colom 1, 08222 Terrassa (Barcelona). Tel.: +34 9373980 43; fax: +34 9373982 \\ 25, e-mail: juan.torrent@upc.edu
}

\begin{abstract}
Ubiquinone and plastoquinone are two of the main electron and proton shuttle molecules in biological systems, and monogalactosyldiacylglycerol (MGDG) is the most abundant lipid in the thylakoid membrane of chloroplasts. Saturated MGDG, ubiquinone-10 (UQ) and MGDG:UQ mixed monolayers at the air/water interface have been studied using Surface Pressure-Area isotherms and Brewster Angle Microscopy. Moreover, the transferred Langmuir-Blodgett films have been observed by Atomic Force Microscopy. The results show that MGDG:UQ mixtures present more fluid phase than pure MGDG indicating a higher order degree for the later. It is also observed an important influence of UQ on the MGDG matrix before UQ collapse pressure and a low influence after this event, due to UQ expulsion from the MGDG matrix. This expulsion leads to a similar remaining UQ content for all the tested mixtures, indicating a limiting content of this molecule in the MGDG matrix at high surface pressures. The thermodynamic studies confirm the stability of the MGDG:UQ mixtures at low surface pressures, although presenting a non-ideal behaviour. Results point to consider UQ as a good candidate for studies of artificial photosynthesis.
\end{abstract}

\section{Keywords}

Biomimetic films, Monogalactosyldiacylglycerol, Ubiquinone, Langmuir-Blodgett film, AFM, BAM 


\begin{abstract}
Abbreviations
$\mathrm{AFM}$, atomic force microscopy; BAM, brewster angle microscopy; $C_{s}^{-1}$, inverse of the compressibility modulus; DGDG, digalactosyldiacylglycerol; $G^{\mathrm{E}}$, excess free energy of mixing; $\Delta \mathrm{G}_{\mathrm{mix}}$, mixing energy; LB, Langmuir-Blodgett; $\mathrm{LC}$, liquid condensed phase; LE, liquid expanded phase; MGDG, monogalactosyldiacylglycerol; $\mathrm{PQ}$, plastoquinone; $\mathrm{S}$, solid phase; $\pi-\mathrm{A}$, surface pressure-area; UQ, Ubiquinone
\end{abstract}

\title{
1. Introduction
}

The light depending reactions of the photosynthetic process take place in the thylakoid membrane of chloroplasts [1]. The lipidic composition of the thylakoid membrane of higher plant cells is based on galactolipids being the most important monogalactosyldiacylglycerol, MGDG $(\approx 50 \%)$, and digalactosyldiacylglycerol (DGDG) $(\approx 25 \%)$. The thylakoid membrane also contains several proteins and molecules, having the main function of transporting and releasing electrons to produce chemical energy for dark reactions. MGDG and DGDG contents affect the function of thylakoid membrane proteins [2], especially the light harvesting complexes of the photosystem. One of the main electron and proton shuttle molecules in green plants is plastoquinone (PQ) [3,4] which is mainly found in chloroplasts. On the other hand, ubiquinone, UQ, is present in eukaryotic cells at the hydrophobic core of the phospholipid bilayer of the inner membrane of mitochondria, where plays the role of electron and proton shuttle $[4,5,6]$.

Several attempts have been done to achieve artificial photosynthesis using several quinones for electron transport instead of using PQ [7-9]. PQ has a quinone ring similar to the simple benzoquinone, but also has a long tail of nine isoprenoid units (Scheme 1A). UQ is very close to PQ having ten isoprenoid units and a similar quinone ring differentiated by the methoxy groups in stead of the methyl groups (Scheme 1B). These chemical structures are supposed to confer a special position to PQ and UQ in the membrane for electron and proton exchange. In order to clarify this point, several studies have been performed to understand PQ or UQ position and the characteristics of these molecules [10-14]. Previous voltammetric results of phospholipid layers containing quinone derivatives [13,15-19] and the fact that UQ size and shape are close to those of PQ, make UQ a suitable candidate for substituting PQ, which isolation process has a huge cost, in studies of artificial photosynthesis. 
Several studies have been performed on galactolipids due to their relevance in photosynthesis and other natural processes like cell growth modulator [20], anti-inflammatory [21,22] and anti-cancer agent [23-26]. One of the most relevant model membrane information is the galactolipid phase behaviour, especially its liquid-crystalline packing properties which has been widely investigated [27-35]. The most important difference between membrane galactolipids from different organisms is the saturation grade of these lipid acyl chains, being commonly polyunsaturated for higher plants and monounsaturated or fully saturated for microorganisms [29, 36,37]. Saturated MGDG (Scheme 1C) has only been used previously for MGDG structure characterization. Unsaturated MGDG has been more widely used because needs no further treatment after isolation, but has the inconvenience of the different saturation grade depending on the natural source and a lower stability. The extent of double bonds in lipid monolayer formation is associated with preventing the formation of ordered phases $[12,27]$.

Some of the cited authors have worked on galactolipids monolayers. Unsaturated galactolipids form monolayers on water surface exhibiting an homogeneous liquid-expanded (LE) phase in agreement with the degree of double bonds in the acyl chains [27,28]. Bottier et al [27] studied MGDG, DGDG and MGDG:DGDG mixture films, and also studied these films inserting proteins (puroindolines) [38]. Gzyl-Malcher et al [28] work revealed behaviour differences between MGDG or DGDG with different acyl chain saturation grade. TomoaiaCotisel et al. [29,31] studied the monolayer properties of saturated galactolipids with different subphases indicating that the nature of the subphase anion produces a variation of the limiting area. Physicochemical properties of lipid-quinone monolayers were studied with the Langmuir technique by Quinn and Esfahani [10] using 1,2-dimyristoylphosphatydilcholine and UQ, achieving interesting results for phospholipid model membrane. Kruk et al. [12] used the LB technique for studying PQ films molecular orientation and Kruk et al. [11] also used the Langmuir technique for MGDG:PQ mixtures to study the PQ content in the MGDG matrix and the charge-transfer complexes in mixed monolayers.

The aim of this work is to study the physicochemical properties of saturated MGDG, UQ and MGDG:UQ mixed monolayers at the air/water interface, correlating the results with topographic images and observing the influence of UQ in the MGDG matrix to decide if UQ can play a similar role than PQ in natural mimicking cell membranes. In our experiments, we 
use commercial saturated MGDG (the acyl chains have been fully hydrogenated) to avoid the differences between saturation grade and chain length depending on the lipid source. The topographic characterization with Atomic Force Microscopy (AFM) and Brewster Angle Microscopy (BAM) is, at the best of our knowledge, the first time being used for this kind of systems to give substantial information about the film structure at several surface pressures. The isotherm data and topographic images obtained for pure fully saturated MGDG provide relevant information of this lipid layers permitting the comparison with partially unsaturated MGDG to understand the different MGDG behaviour according to the unsaturation grade. The results obtained for UQ in MGDG matrix can be of great interest for studies of artificial photosynthesis.<smiles>CCC(C)=CCC1=CC(=O)C(C)=C(C)C1=O</smiles>

A<smiles>CCCCC1=C(C)C(=O)C(OC)=C(OC)C1=O</smiles>

B<smiles>[R]C(=O)OCC(COC1OCC(O)[C@H](O)[C@H](O)[C@H]1O)OC([R])=O</smiles>

$\mathrm{C}$

Scheme 1. A) Plastoquinone-9, B) Ubiquinone-10, C) Monogalactosyldiacylglycerol

\section{Experimental}

\subsection{Materials}

Saturated monogalactosyldiacylglycerol (MGDG), with acyl=stearoyl (18:0), was purchased from Matreya (USA) and ubiquinone-10 (UQ) HPLC grade was from Sigma-Aldrich. 
Chloroform of analytical grade was used in solutions preparation, and water was ultrapure MilliQ® (18.2 M $\Omega \cdot c m)$. Mica sheets were purchased from TED PELLA Inc (CA). Pure components solutions ( $1 \mathrm{mg} / \mathrm{mL})$ were prepared dissolving MGDG and UQ in chloroform in separate glass vials. MGDG and UQ were completely dissolved after three hours. Mixtures were prepared mixing the appropriated volume of each pure component solutions to achieve the desired MGDG:UQ ratio.

\subsection{Monolayer formation}

Langmuir and Langmuir-Blodgett (LB) monolayer formation were carried on a trough (Nima Technology, Cambridge, UK) model 1232D1D2 equipped with two movable barriers. The surface pressure was measured using paper Whatman 1 held by a Wilhelmy balance connected to a microelectronic system registering the surface pressure $\pi$ as $\gamma_{0}-\gamma$, where $\gamma_{0}$ and $\gamma$ are the surface tension values in the absence and presence of insoluble molecules at the air/liquid interface. Subphase used in these experiments was MilliQ® quality water. Previous to the subphase addition, the trough was cleaned twice with chloroform and once with MilliQ® quality water. Residual impurities were cleaned from the air/liquid interface by surface suctioning. The good baseline in the surface pressure-area, $\pi-\mathrm{A}$, isotherms confirms the interface cleanliness. Solutions of MGDG, UQ and MGDG:UQ were prepared using chloroform and spread at the air/liquid interface using a high precision Hamilton microsyringe. LB monolayers were transferred to mica surface at defined surface pressures values. Barrier closing rates were fixed at $50 \mathrm{~cm}^{2} \cdot \mathrm{min}^{-1}\left(11.8 \AA^{2} \cdot \mathrm{molec}^{-1} \cdot \mathrm{min}^{-1}\right)$ for isotherm registration and at $25 \mathrm{~cm}^{2} \cdot \mathrm{min}^{-1}\left(5.9 \AA^{2} \cdot \mathrm{molec}^{-1} \cdot \mathrm{min}^{-1}\right)$ for LB film transfer. No noticeable influence of these compression rates was observed on the isotherm shape. Isotherm recording was carried out adding the solution to the subphase and waiting 15 minutes for perfect spreading and solvent evaporation. LB film transfer was conducted dipping the freshly cleaved mica through the air/liquid interface on the subphase before adding the solution, and five minutes were lagged after pressure setpoint was achieved. Transfer speed was set at 5 $\mathrm{mm} / \mathrm{min}$ linear velocity. The obtained transfer ratios were close to 1 , except for the mixture MGDG:UQ 5:1 molar ratio at low surface pressure which was a bit lower, indicating a good transfer. Experiments were conducted at $21 \pm 0.5^{\circ} \mathrm{C}$ and repeated a minimum of three times for reproducibility control. 
The AFM topographic images of LB films were acquired in tapping mode using a Multimode AFM controlled by Nanoscope IV electronics (Veeco, Santa Barbara, CA) under ambient conditions. Silicon tips with a nominal spring constant of $40 \mathrm{~N} \cdot \mathrm{m}^{-1}$ were used (ACT-W, Applied Nanostructures, Santa Clara, CA). Images were acquired at $1.5 \mathrm{~Hz}$ and at minimum vertical force so as to reduce sample damage. AFM images were obtained from at least two different samples, prepared on different days, and by scanning several macroscopically separated areas on each sample.

\subsection{Brewster angle Microscopy (BAM)}

A Brewster angle microscope, model MICROBAM NIMA-Nanofilm with lateral resolution of $8 \mu \mathrm{m}$ and equipped with a $30 \mathrm{~mW}$ laser emitting p-polarised light at a wavelength $\lambda=659$ $\mathrm{nm}$, was used to visualise the structure of monolayers at the air-water interface. Each image shown in this work corresponds to an area of $2.3 \mathrm{~mm} \times 3.4 \mathrm{~mm}$ of the monolayer.

\section{Results}

\subsection{Thermodynamic analysis}

Figure 1 represents the $\pi$-A isotherms of MGDG, UQ and MGDG:UQ mixtures at different molar ratios. Since UQ is present in biological systems at low content in respect to the lipid matrix, mixtures with low UQ molar ratios have been studied. Information on the identification of states and phase transitions in the monolayers $[39,40]$ can be obtained using the inverse of the compressibility modulus $\left(C_{s}^{-1}\right)$, which is represented in the inset of Figure 1:

$$
C_{s}^{-1}=-A\left(\frac{d \pi}{d A}\right)_{T}
$$

In equation (1), A is the mean area per molecule $\left(\AA^{2} \cdot\right.$ molecule $\left.^{-1}\right), \pi$ is the surface pressure $\left(\mathrm{mN} \cdot \mathrm{m}^{-1}\right)$, and $\mathrm{T}$ is the absolute temperature. 


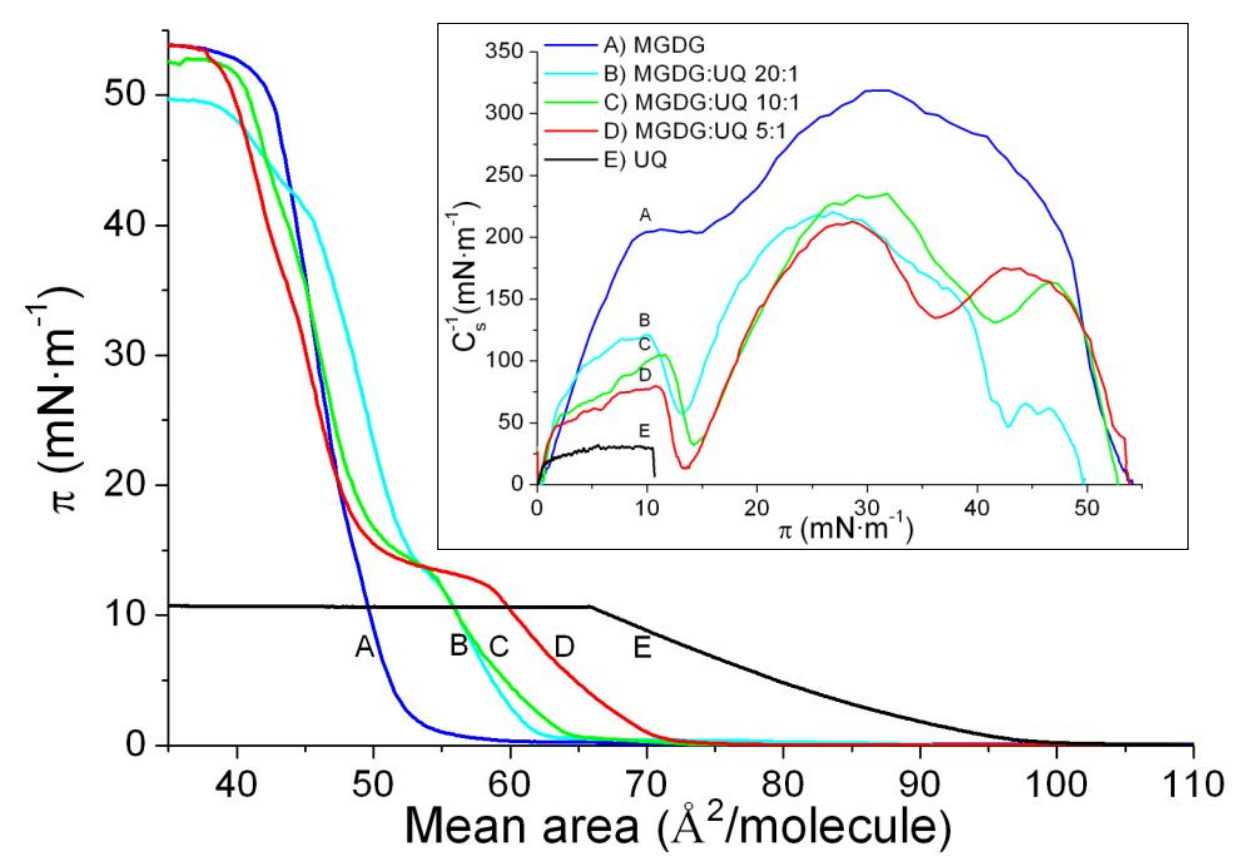

Figure 1. $\pi$-A isotherms for MGDG, UQ and MGDG:UQ mixtures at $21 \pm 0.5^{\circ} \mathrm{C}$. Inset: Inverse of the compressibility modulus vs. surface pressure for MGDG, UQ and MGDG:UQ mixture film isotherms.

UQ pure component isotherm presents a regular increase of the surface pressure with no appreciable inflexion points until the collapse region at ca. $11 \mathrm{mN} \cdot \mathrm{m}^{-1}$. The low collapse surface pressure and the presence of a long plateau indicate a monolayer collapse by multilayer formation [41,42]. The MGDG isotherm shows a lift-off at an area ca. 65 $\AA^{2} \cdot$ molecule $^{-1}$, similar to the value reported by Gzyl-Malcher et al. [28], and presents a regular increase until the collapse region, at ca. $53 \mathrm{mN} \cdot \mathrm{m}^{-1}$, with only a nearly imperceptible inflexion point ca. $13 \mathrm{mN} \cdot \mathrm{m}^{-1}$. Inset of Figure 1 gives a clearer view of inflexion points and also permits to assign the film state according to the $\mathrm{C}_{\mathrm{s}}^{-1}$ values. Thus, MGDG presents a LC state changing to solid (S) state at around $13 \mathrm{mN} \cdot \mathrm{m}^{-1}$. On the other hand, UQ shows only a LE state before the collapse.

The isotherms of MGDG:UQ mixtures describe a regular increase of the surface pressure till $\pi \approx 13 \mathrm{mN} \cdot \mathrm{m}^{-1}$. Here, a plateau is drawn with a length depending on the UQ mixture molar content. After the plateau, the isotherm presents a regular increase resembling the pure MGDG isotherm. According to $\mathrm{C}_{\mathrm{s}}^{-1}$ values, MGDG:UQ mixtures present a LE phase before the plateau, changing to a $\mathrm{LC}$ state ca. $13 \mathrm{mN} \cdot \mathrm{m}^{-1}$. These observations could indicate that at 
the plateau surface pressure, the UQ is being expelled from the MGDG matrix allowing the phase change. This phenomenon has been also observed for mixed films of UQ in DPPC [13]. At $\pi \approx 40 \mathrm{mN} \cdot \mathrm{m}^{-1}$ it is observed another inflexion in the mixed film isotherms, that could indicate some kind of molecular reorientation and also the expulsion of the remaining UQ molecules from the MGDG matrix at this surface pressure. Previous studies have pointed to the existence of a MGDG headgroups reorientation [27]. These observations indicate that UQ difficult the interactions between MGDG molecules to dispose in a more compact organization, and consequently the phase change is hindered in the presence of UQ. MGDG pure component presents larger values of $\mathrm{C}_{\mathrm{s}}^{-1}$ than the mixtures, indicating that pure MGDG form more rigid monolayers than the mixtures. Finally, saturated MGDG:UQ mixtures revealed a collapse pressure of ca. $53 \mathrm{mN} \cdot \mathrm{m}^{-1}$, very close to the value of pure saturated MGDG.

Limiting mean area per molecule for the mixtures can be obtained from the isotherms by the extrapolation to zero pressure of the isotherm slope draw at high pressures, being 53, 54 and $56 \AA^{2} \cdot$ molecule $^{-1}$ for 5:1, 10:1 and 20:1 MGDG:UQ mixtures respectively. These values are similar to each other and also similar to the limiting area value of $52 \AA^{2} \cdot$ molecule $^{-1}$ for the pure MGDG. Comparison with reported values will be presented in the discussion section.

Figures $2 \mathrm{~A}$ and $2 \mathrm{~B}$, representing the mean area per molecule vs the UQ molar fraction in each mixture at several surface pressures, permit the study of the behaviour of MGDG:UQ mixtures. Figure $2 \mathrm{~A}$ (for $\pi<\pi \mathrm{UQ}$ collapse) presents a mean area increment from pure MGDG $\left(\mathrm{X}_{\mathrm{UQ}}=0\right)$ to pure $\mathrm{UQ}\left(\mathrm{X}_{\mathrm{UQ}}=1\right)$. The data points exhibit positive deviations from the ideal behaviour in all cases, showing that MGDG:UQ form non-ideal monolayers at the air/water interface where the net repulsive interaction predominates between the components. Figure $2 \mathrm{~B}$ represents the mean area per molecule vs the UQ molar fraction in each mixture at several surface pressures for $\pi>\pi$ UQ collapse, assuming that UQ area is the area at the surface pressure of the UQ collapse. This figure shows that the mean area per molecule presents negative deviation from the ideal curve except for the lowest $\mathrm{UQ}$ content $\mathrm{X}_{\mathrm{UQ}}=0.05$. 


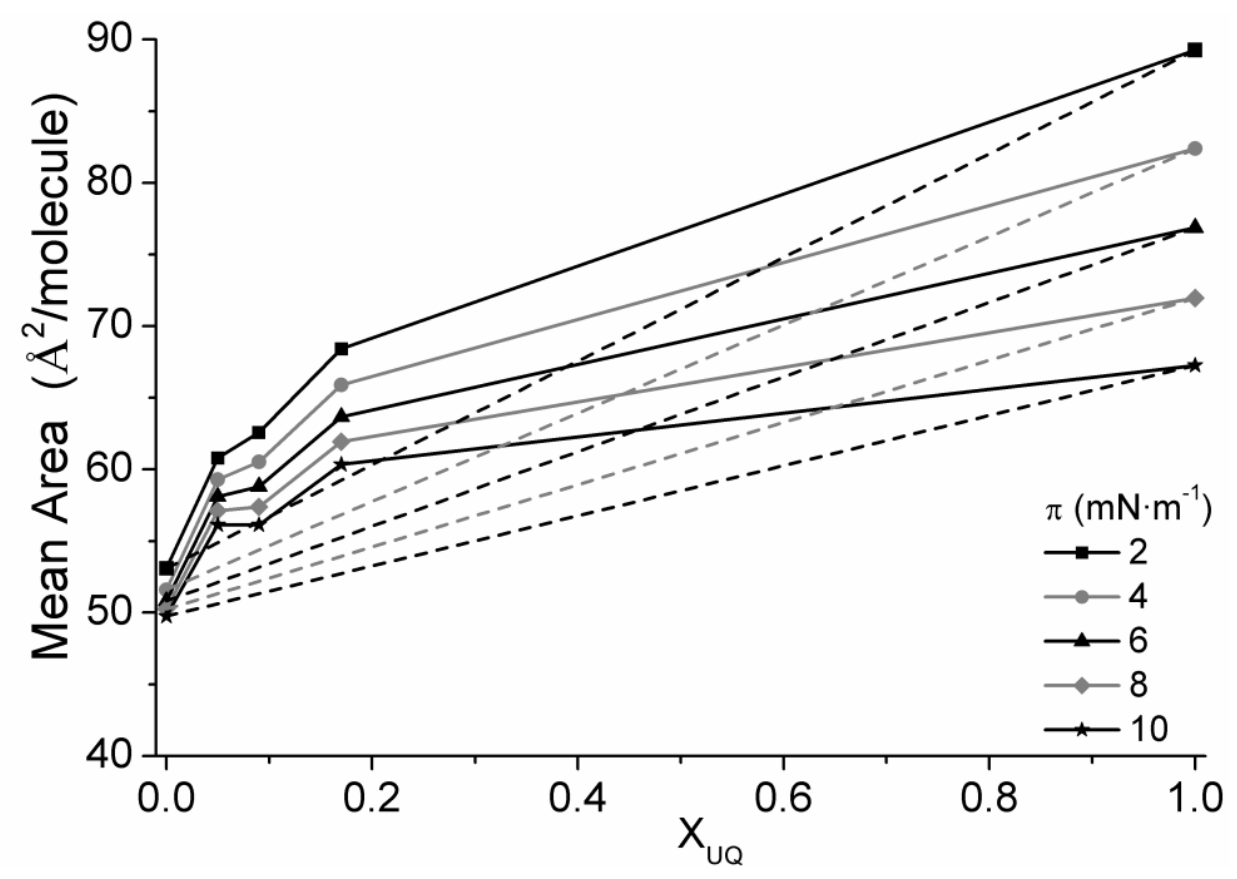

Figure 2A. Plot of the Mean area per molecule vs. the molar fraction for MGDG, UQ and MGDG:UQ mixtures at several surface pressures below UQ collapse. $\pi=2(\boldsymbol{\bullet}), \pi=4(\bullet), \pi=$ $6(\boldsymbol{\Delta}), \pi=8(\diamond), \pi=10(\star) \mathrm{mN} \cdot \mathrm{m}^{-1}$. Discontinuous straight lines represent the ideal behaviour for each surface pressure.

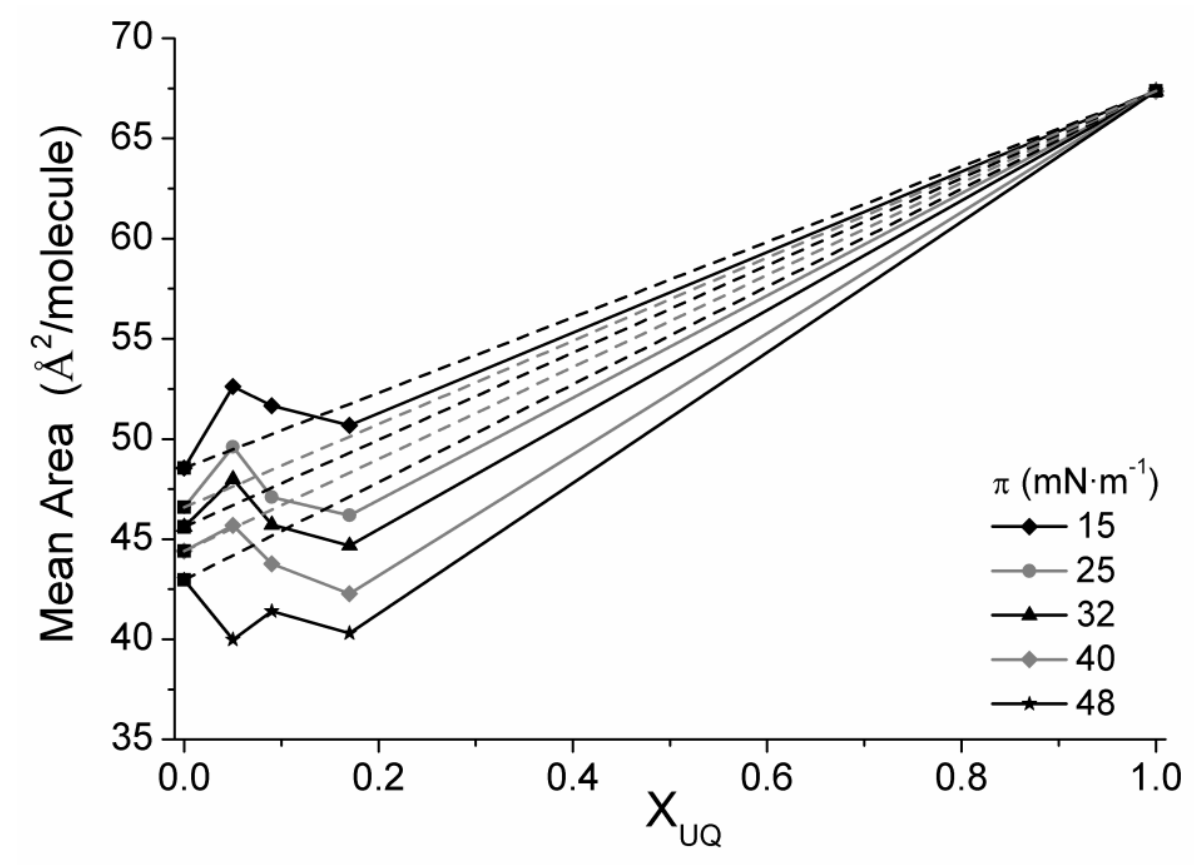

Figure 2B. Plot of the Mean area per molecule vs. the molar fraction for MGDG, UQ and MGDG:UQ mixtures at several surface pressures higher than UQ collapse. $\pi=15(\boldsymbol{\square}), \pi=25$ $(\bullet), \pi=32(\Delta), \pi=40(\bullet), \pi=48(\star) \mathrm{mN} \cdot \mathrm{m}^{-1}$. Discontinuous straight lines represent the ideal behaviour for each surface pressure. 
In the case of a mixed monolayer of two components, $\Delta \mathrm{G}_{\mathrm{mix}}$ can be expressed as $[43,44]$ :

$\Delta \mathrm{G}_{\text {mix }}=\Delta \mathrm{G}_{\mathrm{id}}+\mathrm{G}^{\mathrm{E}}$

$\Delta \mathrm{G}_{\mathrm{id}}=\mathrm{RT}\left(\mathrm{X}_{1} \ln \mathrm{X}_{1}+\mathrm{X}_{2} \ln \mathrm{X}_{2}\right)$

where $\Delta \mathrm{G}_{\mathrm{id}}$ is the ideal free energy of mixing which can be evaluated from equation (3), being $\mathrm{R}$ the gas constant and $\mathrm{T}$ the absolute temperature, and $\mathrm{G}^{\mathrm{E}}$ is the excess free energy of mixing. $\mathrm{G}^{\mathrm{E}}$ is a representation of the free energy deviation of a real mixed system from an ideal mixed one. The $G^{E}$ at a specific surface pressure can be calculated from the $\pi$-A isotherm data through equations (4) and (5) for a system of two components, being $\mathrm{N}_{\mathrm{A}}$ the Avogadro's number and $A^{E}$ the excess area, $A_{12}$ the mean area per molecule for the mixture and $A_{1}$ and $A_{2}$ the area per molecule for the individual components.

$$
\begin{aligned}
& A^{E}=A_{12}-\left(x_{1} A_{1}+x_{2} A_{2}\right) \\
& G^{E}=N_{A} \int_{0}^{\pi} A^{E} d \pi
\end{aligned}
$$

Figure $3 A$ illustrates $G^{E}$ vs. the UQ molar fraction only for surface pressures below the UQ collapse surface pressure, giving information about the interactions. In this case, the $\mathrm{G}^{\mathrm{E}}$ values are always positive, $\mathrm{G}^{\mathrm{E}}>0$, indicating that interactions between MGDG and UQ are not favoured compared with an ideal mixture.

Figure 3B depicts the $\Delta \mathrm{G}_{\mathrm{mix}}$ vs. $\mathrm{X}_{\mathrm{UQ}}$ plot for mixed monolayers at the air/water interface giving information about the mixing behaviour before the UQ collapse surface pressure. $\Delta \mathrm{G}_{\text {mix }}$ presents negative values for all compositions indicating that the mixed monolayers are more stable compared with non-mixed, due to the entropic component. The absolute values of $\Delta \mathrm{G}_{\mathrm{mix}}$ decrease as surface pressure does, being caused by the longer intermolecular distances associated with low surface pressures [27,45]. To summarize the thermodynamic study, $\Delta \mathrm{G}_{\mathrm{mix}}$ realize that MGDG and UQ are mixed and stable before the UQ collapse surface pressure despite of $\mathrm{G}^{\mathrm{E}}$ indicates that interactions between MGDG and UQ are not favoured. The interactions in the mixtures are more favoured at low UQ molar ratios according with quinone molar ratio in real biological membranes [46]. 


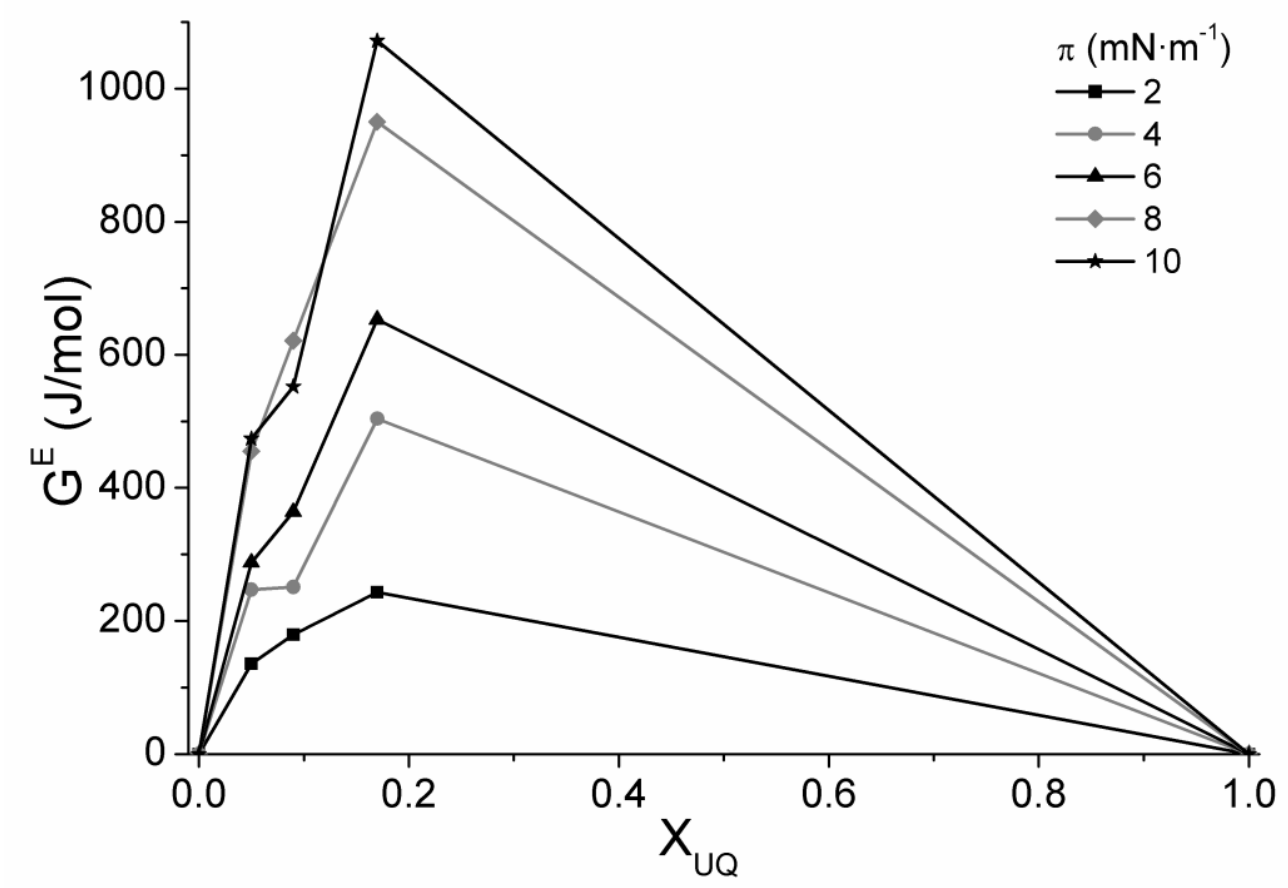

Figure 3A. Plot of the excess energy vs. the molar fraction for MGDG, UQ and MGDG:UQ mixtures at several surface pressures below the UQ collapse $\pi=2(\boldsymbol{\bullet}), \pi=4(\bullet), \pi=6(\boldsymbol{\Delta}), \pi$ $=8(\diamond), \pi=10(\star) \mathrm{mN} \cdot \mathrm{m}^{-1}$.

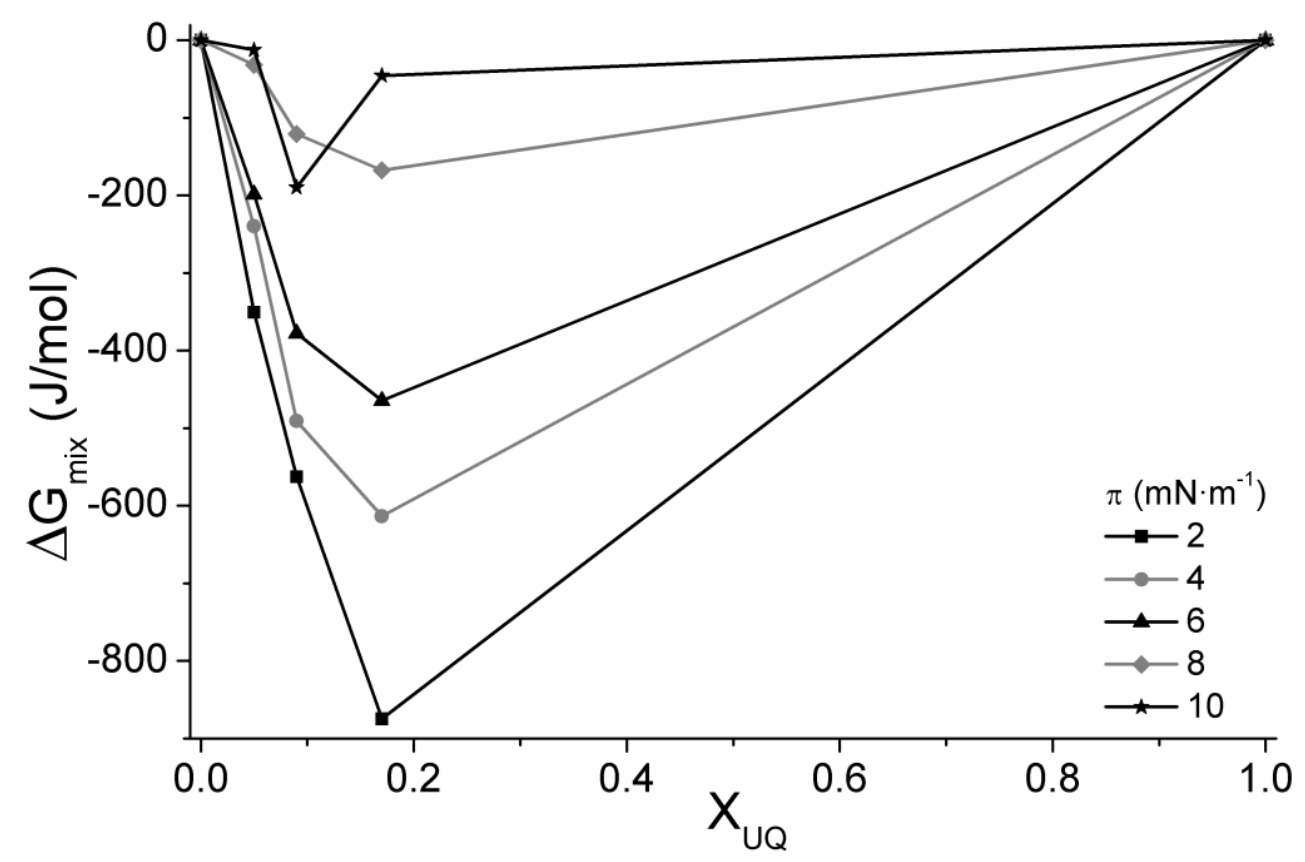

Figure 3B. Plot of the mixing energy vs. the molar fraction for MGDG, UQ and MGDG:UQ mixtures at several surface pressures below the UQ collapse $\pi=2(\boldsymbol{\bullet}), \pi=4(\bullet), \pi=6(\boldsymbol{\Delta}), \pi$ $=8(\diamond), \pi=10(\star) \mathrm{mN} \cdot \mathrm{m}^{-1}$. 


\subsection{Topographic characterization}

MGDG and MGDG:UQ monolayer formation processes have been studied in situ using BAM images (Figures 4 and 5) at several surface pressures. These images permit to distinguish the phases deduced from the isotherm at the air-water interface. Figure 4A presents a zoom of the MGDG:UQ 10:1 isotherm from Figure 1, corresponding to the gas phase zone, that appears for $\pi<0.6 \mathrm{mN} / \mathrm{m}$ and starts at $75 \AA^{2} \cdot$ molecule $^{-1}$. The values of $\mathrm{C}_{\mathrm{s}}^{-1}$ (Inset in Figure 4A) agree with those of a gas phase. This phase appears in the BAM image (Figure 4B) as a foam structure. The subsequent MGDG:UQ film states and phase changes are presented in Figure 5. Figure 5A corresponds to the LE phase, Figure 5B shows the LE to LC phase change being both phases present at ca. $\pi \approx 13 \mathrm{mN} \cdot \mathrm{m}^{-1}$, and above this surface pressure, the monolayer is practically homogeneous, and corresponds to the LC state (Figure 5C).
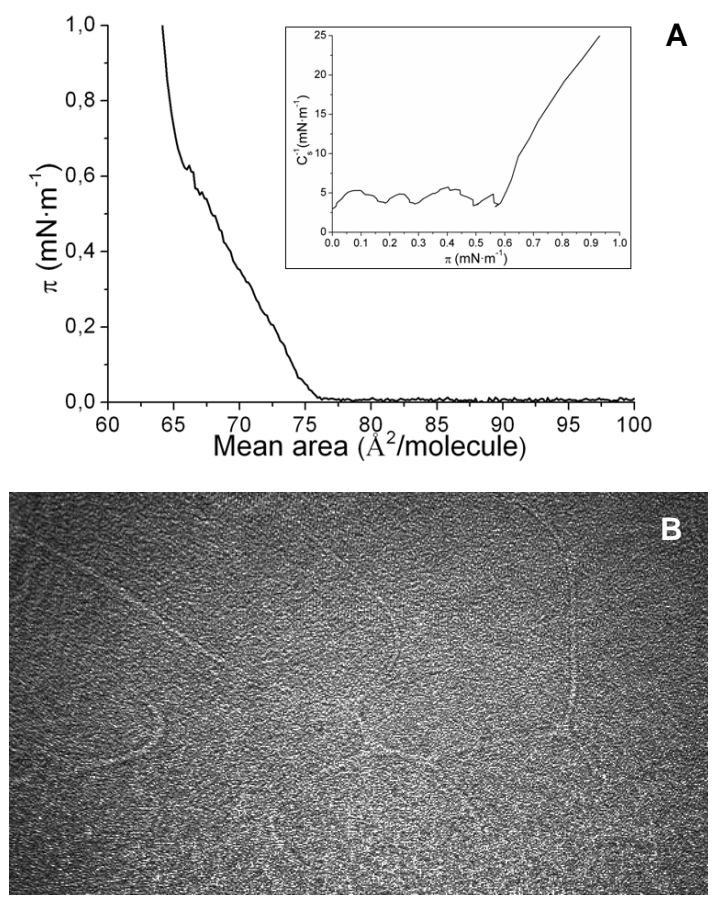

Figure 4. A) Lift-off zone zoom of the MGDG:UQ 10:1 $\pi$-A isotherm. Inset: Inverse of the compressibility modulus vs. surface pressure. B) BAM image of the monolayer MGDG:UQ $10: 1$ at $21^{\circ} \mathrm{C}$ and at the lift-off zone $\left(\pi=0.25 \mathrm{mN} \cdot \mathrm{m}^{-1}\right.$ and $\left.\mathrm{A}=72 \AA^{2} \cdot \mathrm{molecule}^{-1}\right)$. 


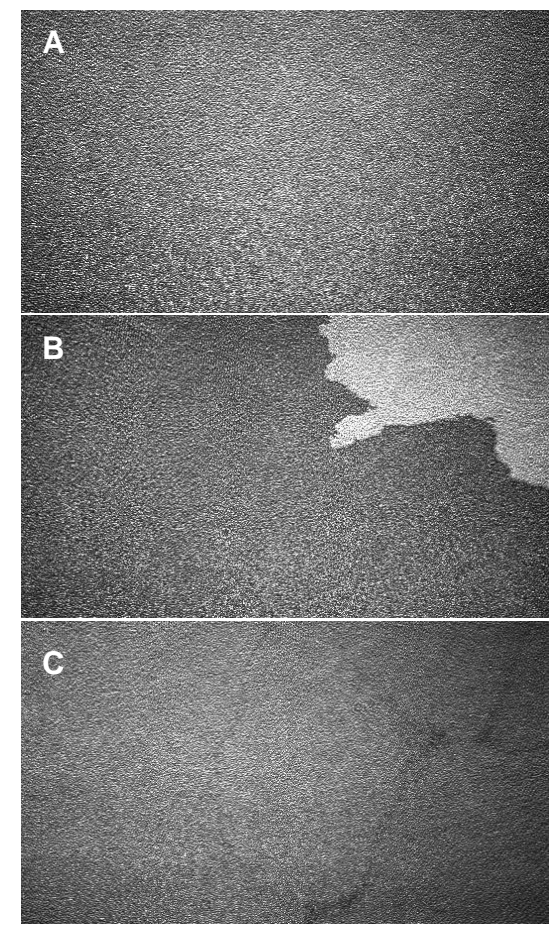

Figure 5. BAM images of a MGDG:UQ 10:1 mixture monolayer at $21^{\circ} \mathrm{C}$ and at selected phase states. A) $\pi=4.7 \mathrm{mN} \cdot \mathrm{m}^{-1}$ and $\mathrm{A}=61 \AA^{2} \cdot$ molecule $^{-1}$, B) $\pi=13.9 \mathrm{mN} \cdot \mathrm{m}^{-1}$ and $\mathrm{A}=53$ $\AA^{2} \cdot$ molecule $^{-1}$, C) $\pi=40.0 \mathrm{mN} \cdot \mathrm{m}^{-1}$ and $\mathrm{A}=44 \AA^{2} \cdot$ molecule $^{-1}$.

AFM provides valuable information about the film nanometric structure, so that, LB films of pure components and their mixtures were transferred onto mica at selected surface pressure values and the corresponding AFM images where obtained. The film structure is studied in correspondence with the isotherm characteristics. Figure 6 shows the packing of the pure saturated MGDG LB film. At $\pi=6 \mathrm{mN} \cdot \mathrm{m}^{-1}$ (Fig 6A) we observe two phases in the monolayer. According to the isotherm a LC phase corresponds to this surface pressure, thus we could assume that the two observed phases are induced in the transfer process on mica, which promote the LC to $\mathrm{S}$ phase change. At $\pi=15 \mathrm{mN} \cdot \mathrm{m}^{-1}$ (Fig 6B) the LC phase is compacting to $\mathrm{S}$ phase in a higher degree. Images at $\pi=25 \mathrm{mN} \cdot \mathrm{m}^{-1}$ (Fig 6C) and at $\pi=40$ $\mathrm{mN} \cdot \mathrm{m}^{-1}$ (Fig 6D) shows a uniform monolayer in the solid state.

Pure UQ, which presents a LE phase before the collapse pressure, has also been studied using the LB technique (Figure 7). UQ presents a uniform film which is typical of LE states. 


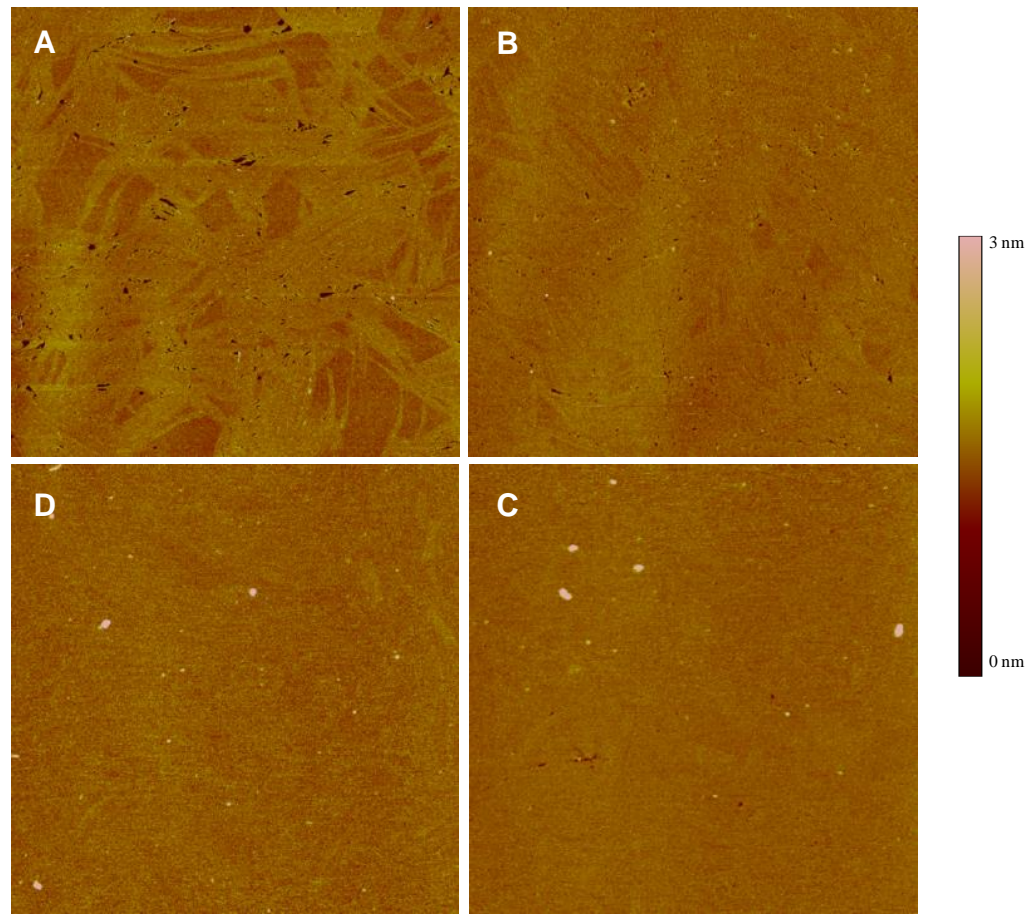

Figure 6. AFM images $(10 \mu \mathrm{m} \times 10 \mu \mathrm{m})$ of $\mathrm{LB}$ films transferred on mica for MGDG at $21^{\circ} \mathrm{C}$ and for $\pi=$ A) 6, B) 15, C) 25 and D) $40 \mathrm{mN} \cdot \mathrm{m}^{-1}$.

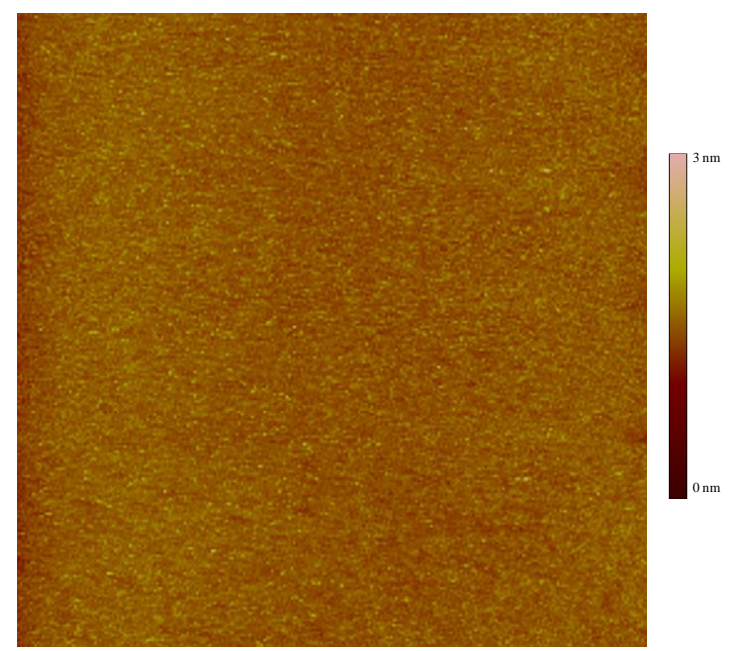

Figure 7. AFM image $(5 \mu \mathrm{m} \times 5 \mu \mathrm{m})$ of pure UQ at $\pi=6 \mathrm{mN} \cdot \mathrm{m}^{-1}$ and $21^{\circ} \mathrm{C}$.

Figure 8 shows AFM images of pure MGDG (Figure 8A) and the different MGDG:UQ mixtures (Figures 8B,C,D), extracted at $\pi=6 \mathrm{mN} \cdot \mathrm{m}^{-1}$ showing the influence of the UQ content on the MGDG matrix. In comparison to the MGDG monolayer (Figure 8A), where only some very small holes are seen, MGDG:UQ mixtures show zones with a depth similar to 
the holes in Figure 8A (see Table I) and which area increases with the UQ content. This fact will be explained in the discussion section. On the other hand, the monolayer packing process for the mixtures can be followed in Figure 9 corresponding to AFM images of the MGDG:UQ 5:1 mixture at several surface pressures. Figure 9A shows the film state at $\pi=6 \mathrm{mN} / \mathrm{m}$, where a LE phase corresponds according to the isotherm. At a surface pressure of $\pi=15 \mathrm{mN} / \mathrm{m}$ (above the inflexion point presented in the isotherm at $\pi \approx 13 \mathrm{mN} \cdot \mathrm{m}^{-1}$ ), Figure 9B shows that the packing of the film has been increased considerably, which continues at $\pi=25 \mathrm{mN} / \mathrm{m}$ (Figure 9C) where the MGDG:UQ film is more continuous, having a few pin holes density. At $\pi=40 \mathrm{mN} / \mathrm{m}$ (Figure 9D) the LC film is compact, with a very low pin holes density, and forms filament structures which have a height of ca. $0.25 \mathrm{~nm}$ in respect to the uniform zone. This observation can be correlated with the inflexion point observed in the isotherms around this surface pressure. Bottier et al [27] have also observed similar structures for the MGDG and MGDG:DGDG mixtures at high surface pressures $\left(35 \mathrm{mN} \cdot \mathrm{m}^{-1}\right)$.

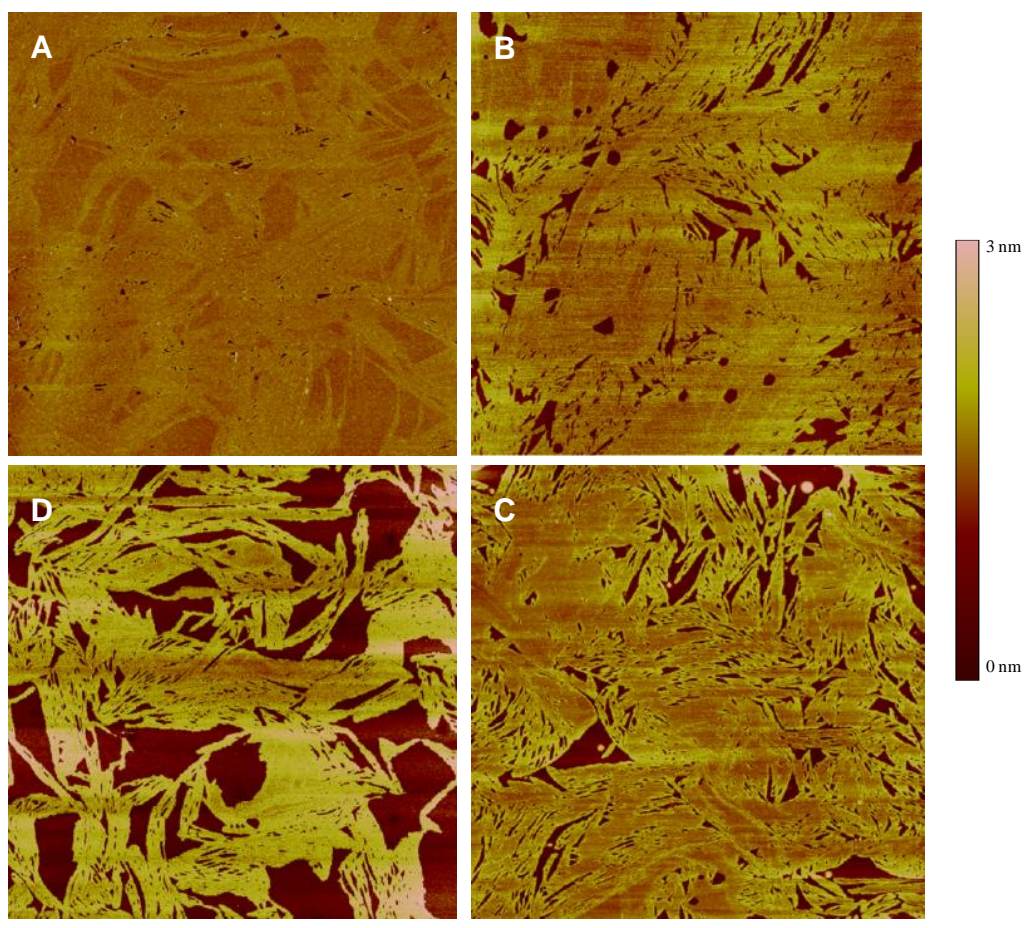

Figure 8. AFM images $(10 \mu \mathrm{m} \times 10 \mu \mathrm{m})$ of LB films transferred on mica at $21^{\circ} \mathrm{C}$ and $\pi=6$ $\mathrm{mN} \cdot \mathrm{m}^{-1}$ for A) pure MGDG, B) MGDG:UQ 20:1, C) MGDG:UQ 10:1, D) MGDG:UQ 5:1. 

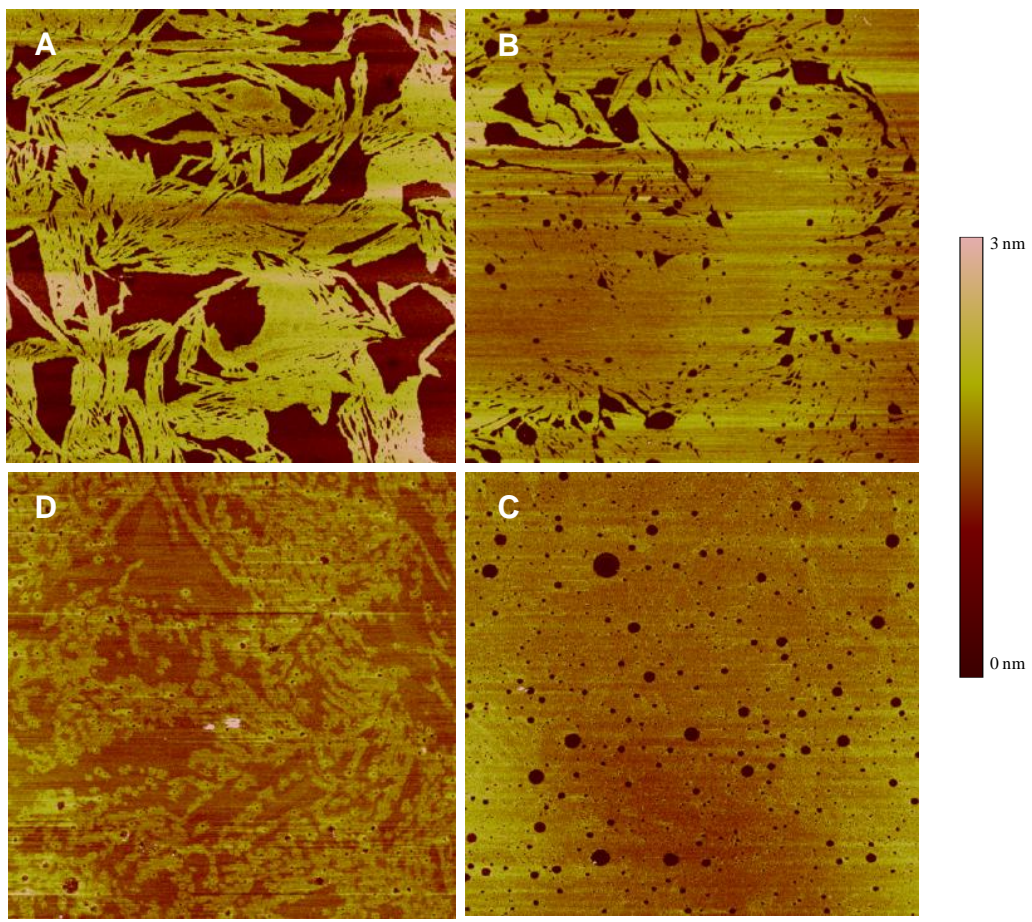

Figure 9. AFM images $(10 \mu \mathrm{m} \times 10 \mu \mathrm{m})$ of MGDG:UQ 5:1 LB films transferred on mica at $21^{\circ} \mathrm{C}$ for several surface pressures A) $\left.\left.\left.\pi=6 \mathrm{mN} \cdot \mathrm{m}^{-1} \mathrm{~B}\right) \pi=15 \mathrm{mN} \cdot \mathrm{m}^{-1} \mathrm{C}\right) \pi=25 \mathrm{mN} \cdot \mathrm{m}^{-1} \mathrm{D}\right) \pi$ $=40 \mathrm{mN} \cdot \mathrm{m}^{-1}$.

Table I. Monolayer height $( \pm 0.1 \mathrm{~nm})$ measured relatively to the mica surface from AFM images, for the pure MGDG and the MGDG:UQ mixtures LB films. Blank cells indicate that height cannot be measured due to the compactness of the monolayer.

\begin{tabular}{|l|l|l|l|l|}
\hline$\pi\left(\mathrm{mN} \cdot \mathrm{m}^{-1}\right)$ & $\begin{array}{l}\text { MGDG } \\
(\mathrm{nm})\end{array}$ & $\begin{array}{l}\text { MGDG:UQ 20-1 } \\
(\mathrm{nm})\end{array}$ & $\begin{array}{l}\text { MGDG:UQ 10-1 } \\
(\mathrm{nm})\end{array}$ & $\begin{array}{l}\text { MGDG:UQ 5-1 } \\
(\mathrm{nm})\end{array}$ \\
\hline 6 & 1.3 & 1.2 & 1.5 & 1.5 \\
\hline 15 & -- & 1.4 & 1.4 & 1.6 \\
\hline 25 & -- & -- & -- & 1.5 \\
\hline
\end{tabular}

Table II shows the monolayer compactness through the percentage of mica surface covered by the monolayer calculated from AFM images. A monotonically increment of the coverage can be seen for each sample when increasing the surface pressure. Moreover, for the same surface pressure, an increment of the UQ molar content produces an important decrease of the coverage of the monolayer, especially at low surface pressures, confirming the deductions 
from the isotherms that UQ disturbs the MGDG compactness. This UQ distortion effect in MGDG matrix has not a proportional increase when increasing UQ content. Figure 2A show that mean area per molecule for the mixtures 20:1 and 10:1 are very close, whereas 5:1 has an important increase in comparison with 20:1 and 10:1. This effect is also seen in Table II where the monolayer coverage area for 20:1 and 10:1 are also close and 5:1 is far from these values, at low surface pressures.

Table II. Monolayer coverage on the mica surface for the pure MGDG and the MGDG:UQ mixtures, calculated from AFM images.

\begin{tabular}{|l|l|l|l|l|}
\hline$\pi\left(\mathrm{mN} \cdot \mathrm{m}^{-1}\right)$ & $\begin{array}{l}\text { MGDG } \\
\%\end{array}$ & $\begin{array}{l}\text { MGDG:UQ 20-1 } \\
\%\end{array}$ & $\begin{array}{l}\text { MGDG:UQ 10-1 } \\
\%\end{array}$ & $\begin{array}{l}\text { MGDG:UQ 5-1 } \\
\%\end{array}$ \\
\hline 6 & 98 & 88 & 88 & 63 \\
\hline 15 & 99 & 92 & 95 & 89 \\
\hline 25 & 100 & 99 & 96 & 96 \\
\hline 40 & 100 & 100 & 100 & 99 \\
\hline
\end{tabular}

\section{Discussion}

Galactolipid molecules are oriented at the air-water interface with the sugar residues in the aqueous phase and the long chains extending into the air. From our experiments it is observed that MGDG presents a LC phase changing to solid film at $\pi>13 \mathrm{mN} \cdot \mathrm{m}^{-1}$, in agreement with the results obtained for saturated MGDG [29,31]. Also, our results for the collapse pressure are in agreement with previous results for saturated MGDG [29] and for pure UQ [10]. On the contrary, reported results in literature for unsaturated MGDG $[11,27,28]$ showed a continuous LE phase according with the double bonds present in its structure, and also showed a collapse pressure of ca. $44 \mathrm{mN} \cdot \mathrm{m}^{-1}$, which is lower than the values obtained in our results due to the unsaturations. These differences have been explained by the presence of unsaturations in the acyl chains of polar lipids which prevented them from close packing at the interface. It is known that in natural membranes variations in the saturation grade of the acyl chains and the 
ratio MGDG/DGDG are used to maintain membrane fluidity to adapt to environment changes [2].

The limiting area per molecule obtained in our experiments for MGDG $\left(52 \AA^{2} \cdot\right.$ molecule $\left.^{-1}\right)$ is far from the $82 \AA^{2} \cdot$ molecule $e^{-1}$ shown by Kruk et al. [11], $82 \AA^{2} \cdot$ molecule $^{-1}$ shown by Bottier et al. [27] and the $84 \AA^{2} \cdot$ molecule ${ }^{-1}$ shown by Fylek et al. [47]. We use MGDG completely saturated whereas Kruk et al. used unsaturated MGDG (unsaturated degree not specified), Bottier et al. and Fylek et al. used a MGDG with ca. 2 and ca. 1 unsaturations per molecule, respectively. Tomoaia-Cotisel et al. [29] using a completely saturated MGDG obtained a limiting molecular area of $49 \AA^{2}$. molecule ${ }^{-1}$, being this value very close to our experimental one. These results confirm that limiting area is affected by double bonds presence. The differences observed in the compressibility modulus between the different previous works have been also attributed to the unsaturations per molecule present in the acyl chains of the MGDG. On the other hand, in our experiments UQ presents a limiting area per molecule of ca. $90 \AA^{2} \cdot$ molecule $e^{-1}$, value that is slightly higher than the value of $71 \AA^{2} \cdot$ molecule ${ }^{-1}$ reported by Roche et al. [48], being this discrepancy probably caused by the different subphase $\mathrm{pH}$ value, but the collapse pressure $\left(11 \mathrm{mN} \cdot \mathrm{m}^{-1}\right)$ coincides with that one reported by Roche et al. in the same work [48].

The collapse pressure of a mixed monolayer of different components is related to the miscibility of their components [28]. As saturated MGDG:UQ mixtures revealed a collapse pressure of ca. $53 \mathrm{mN} \cdot \mathrm{m}^{-1}$, very close to the pure saturated MGDG, therefore this argument can be used to elucidate the expulsion of one of the components in a mixed film. Maintaining temperature and external pressure constant, the number of degrees of freedom $F$ of the monolayer system is given by the equation $(6)[28,49,50]$ :

$\mathrm{F}=\mathrm{C}_{\mathrm{B}}+\mathrm{C}_{\mathrm{S}}-\mathrm{P}_{\mathrm{B}}-\mathrm{P}_{\mathrm{S}}+1(6)$

where $C_{B}$ is the number of components in the bulk, $C_{S}$ is the number of components confined to the surface, $P_{B}$ is the number of bulk phases, and $P_{S}$ is the number of monolayer phases in equilibrium with each other. In our case, at the air/water interface, $C_{B}=2$ (air and water), $C_{S}$ $=2\left(\right.$ MGDG and UQ), and $\mathrm{P}_{\mathrm{B}}=2$ (gas and liquid), thus $\mathrm{F}=3-\mathrm{P}_{\mathrm{S}}$. According to that, homogenous mixed films achieve the collapse equilibrium with $\mathrm{P}_{\mathrm{S}}=2$ (condensed and collapsed state) so the system will have one degree of freedom. According to our results, the 
collapse pressure is practically fixed, discarding the experimental deviations, for pure MGDG and MGDG:UQ mixtures. This indicates zero degrees of freedom. Following the previous reasoning, $\mathrm{P}_{\mathrm{S}}=3$. So that, at the collapse equilibrium coexist MGDG (LC), MGDG (collapse) and expelled UQ. The same statements can be also applied to the phase change zone at $\pi=13$ $\mathrm{mN} \cdot \mathrm{m}^{-1}$, where the $\pi$ is fixed indicating zero degrees of freedom. Thus $\mathrm{P}_{S}=3$ which indicate that 3 phases coexist: LE, LC and expelled UQ, confirming the beginning of the UQ expulsion at this surface pressure.

Fig 2B show the UQ behaviour in the mixture after UQ collapse pressure presenting negative deviation from the ideal curve, except for $\mathrm{X}_{\mathrm{UQ}}=0.05$ indicating that $\mathrm{UQ}$ has been partially squeezed from the MGDG matrix for all the cases, but in the case of $\mathrm{X}_{\mathrm{UQ}}=0.05$, a bit larger percentage of UQ molecules remains inside the MGDG matrix probably due to the initial low UQ presence in the MGDG matrix formation. This fact was also observed for MGDG:PQ mixtures [11]. The similar values of $\mathrm{Cs}^{-1}$ obtained for all the mixtures after the first inflexion point (ca. $13 \mathrm{mN} \cdot \mathrm{m}^{-1}$ ) indicate that after the main UQ expulsion at this surface pressure, a similar content of UQ remains for all compositions. The change of the mean area tendency between $\pi=40$ and $48 \mathrm{mN} \cdot \mathrm{m}^{-1}$ for $\mathrm{X}_{\mathrm{UQ}}=0.05$ can be explained by the expulsion of the remaining UQ molecules from the MGDG matrix as it was discussed previously, and coincides with the second inflexion point seen in the inset of Figure 1, that occurs at surface pressure of $\pi \approx 40 \mathrm{mN} \cdot \mathrm{m}^{-1}$.

The MGDG, PQ and MGDG:PQ mixtures described by Kruk et al. [11] show several differences in comparison with the results obtained here for MGDG:UQ. PQ has a collapse pressure of $1 \mathrm{mN} \cdot \mathrm{m}^{-1}[11,51]$, quite lower than that of UQ $\left(11 \mathrm{mN} \cdot \mathrm{m}^{-1}\right)$. This difference is determinate by the higher hydrophobic character of PQ vs. UQ due to UQ has substituents in its quinone ring that are able to establish hydrogen bonds, permitting a major hydrophilic character than PQ. Kruk et al. used the partially unsaturated MGDG which show a lower collapse pressure than our saturated MGDG. MGDG:PQ mixtures present a positive deviation from the additivity rule (pressures of complete miscibility). This phenomenon also occurs with UQ as has been shown in Figure 2A being explained by the difference in the chain lengths of the components (UQ molecule is two times longer than MGDG).

Figure 6 shows the packing of the pure saturated MGDG LB film. Holes observed in Figure $6 \mathrm{~A}$ (due to imperfections in the film) have a depth of $1.3 \mathrm{~nm}$. On the other hand, the higher 
phase (S phase, bright colour in Figure 6A) has a height of $0.2 \mathrm{~nm}$ in respect to the shorter phase (LC phase, dark colour in Figure 6A). The length of the MGDG molecule can be calculated with the Jmol program and databases [52], obtaining a value of $1.9 \mathrm{~nm}$. From simple geometrical considerations and the previous values, we deduce that the MGDG molecules at $\pi=6 \mathrm{mN} \cdot \mathrm{m}^{-1}$ present a tilt (in respect to the vertical) of ca. $47^{\circ}$ for the $\mathrm{S}$ phase and of ca. $55^{\circ}$ for the LC phase. In contrast with unsaturated MGDG, saturated MGDG presents a compact film during all the formation process whereas unsaturated form protrusions of minimum size $50 \mathrm{~nm}$ with a height of 4-7 $\AA$ as seen by Bottier et al. [27]. They discard the influence of the unsaturations in the protrusions emergence, concluding that MGDG headgroups are the reason for this appearance. In our study we used MGDG which have the same headgroup but with saturated acyl chains and the AFM images presented here (Figure 6) show neither protrusions nor any strange structure in the whole formation process. The presence of filament structures at high surface pressures in our mixtures (Figure 9D), which have a height of ca. $2.5 \AA$ in respect to the uniform zone, are similar in some aspects to those observed by Bottier et al. [27] in unsaturated MGDG pure. The unsaturations on UQ molecules can explain the formation of these filaments. Therefore our results lead us to propose that the unsaturations are responsible for the different topography observed in AFM images between MGDG saturated and unsaturated.

Figure 8 shows the differences in film formation at $\pi=6 \mathrm{mN} \cdot \mathrm{m}^{-1}$ for MGDG and the different mixtures. Dark zones in pure MGDG (Figure 8A) are the LC phase, fair zones correspond to $\mathrm{S}$ and black small areas (holes) correspond to mica surface In mixtures, fair zones are supposed to be LE phase and dark zones mica surface. But Table I shows, in general, higher monolayers for the mixtures. This fact, and the presence of wider dark zones when the UQ content increases, indicates that at the transfer process the presence of the mica substrate leads a phase change from the LE deduced from the isotherms (Figure 1) and seen in BAM images (Figure 5) to the LC. Also, the presence of the long tails of UQ molecules can contribute to measure a higher monolayer. Values in Table I also show the monolayer heights at several surface pressures during the formation of the MGDG:UQ mixture monolayers. The fact that the heights at higher surface pressure values are similar to those at $\pi=6 \mathrm{mN} \cdot \mathrm{m}^{-1}$ and attains a practically common value, discarding the experimental deviations, seems to support the previous hypothesis that the presence of the mica substrate leads a phase change. 


\section{Conclusions}

Saturated MGDG monolayers present a LC phase before the phase change to solid at $\pi \approx 13$ $\mathrm{mN} \cdot \mathrm{m}^{-1}$. Contrarily, MGDG:UQ mixture monolayers present more fluid phases, being LE before the phase change to LC at $\pi \approx 13 \mathrm{mN} \cdot \mathrm{m}^{-1}$. The BAM images confirm, in real time, the phase changes observed. In MGDG:UQ mixtures, the LE to LC phase change implies the main UQ expulsion from the MGDG matrix. The similar isotherm slope and the values of $\mathrm{Cs}^{-1}$ obtained for all the mixtures after the first inflexion point (ca. $\pi \approx 13 \mathrm{mN} \cdot \mathrm{m}^{-1}$ ) indicate that after the main UQ expulsion, a similar content of UQ remains for all compositions.

The thermodynamic studies evidence that MGDG and UQ mix and form stable, although nonideal, mixtures before the UQ collapse surface pressure. The AFM images indicate that the substrate may induce a phase change in monolayers when transferred on mica, and show the distortions caused by UQ in the MGDG matrix. The BAM and AFM images show, at the best of our knowledge, the first topographic images for galactolipid-quinone mixtures. These techniques allow us to confirm some of the information extracted from the isotherms.

The differences shown by our results compared with the obtained by Kruk et al. [11] for MGDG:PQ mixtures are mainly caused by the difference in the MGDG acyl chain saturation grade, and, despite the limitations of the monolayer system as natural model membrane, the MGDG:UQ mixtures are physically suitable for substituting the MGDG:PQ system in artificial photosynthesis studies. Future research will be conducted to study the electrochemical behaviour of this system.

\section{Acknowledgements}

The authors thank the economical support of the Spanish Government trough the project CTQ2007-68101-C02 and to Nanometric Techniques Unit of the Scientific-Technical Services, University of Barcelona, for AFM technical support. J. Hoyo thanks to Universitat Politècnica de Catalunya its $\mathrm{PhD}$ grant. 


\section{References}

[1] J. M. Berg, J.L. Tymoczko, L.Stryer, Biochemistry 5th edition, W. H. Freeman, New York, 2002.

[2] T. Páli, G. Garab, L.I. Horváth, Z. Kota, Cell. Mol. Life Sci. 60 (2003) 1591.

[3] J. Kruk, K. Strzałka, R.M. Leblanc, Biochim. Biophys. Acta 1142 (1993) 6.

[4] E. Swiezewska, G. Dallner, B. Andresson, L. Ernster, J. Biol. Chem. 268 (1993) 1494.

[5] M. Jemiola-Rzeminska, J. Kruk, M. Skowronek, K. Strzalka, Chem. Phys. Lipids 79 (1996) 55 .

[6] B. Nowicka, J. Kruk, Biochim. Biophys. Acta 1797 (2010) 1587.

[7] R Jono, K. Yamashita, J. Phys. Chem. 116 (2012) 1445.

[8] T. Nagata, Y. Kikuzawa, Biochim. Biophys. Acta 1767 (2007) 648.

[9] D. Gust, T. A. Moore and A. L. Moore, Acc. Chem. Res., 42 (2009) 1890.

[10] P. J. Quinn and M. A. Esfahani, Biochem. J. 185 (1980) 715.

[11] J. Kruk , K. Strzałka, R.M. Leblanc, Biochim. Biophys. Acta. 1112 (1992) 19.

[12] J. Kruk , K. Strzałka, R.M. Leblanc, Biophys. Chem. 45 (1993) 235.

[13] J. Hoyo, E. Guaus, J. Torrent-Burgues, F. Sanz, J. Electroanal. Chem. 669 (2012) 6-13.

[14] J. Lipkowski, Phys. Chem. Chem. Phys. 12 (2010) 13874.

[15] J. Hoyo, J. Torrent-Burgués and F. Sanz, Quinones redox behaviour in supported lipid planar bilayers, in M.A. Esteso, Publicaciones Universidad de Alcalá de Henares 2011, Vol.1, pp. 848.

[16] Y. Suemori, M. Nagata, M. Kondo, S. Ishigure, T. Dewa, T. Ohtsuka, M. Nango, Colloids Surf. B. 61(2008) 106.

[17] G.J. Gordillo, D.J. Schiffrin, Faraday Discuss. 116 (2000) 89.

[18] L. Becucci, F. Scaletti, R. Guidelli, Biophys. J. 101 (2011) 134.

[19] D. Marchal, W. Boireau, J. M. Laval, J. Moiroux, C. Bourdillon, Biophys. J. 72 (1997) 2679.

[20] C. Murakami, T. Kumagai, T. Hada, U. Kanekazu, S. Nakazawa, S.Kamisuki, N. Maeda, X. Xu, H. Yoshida, F. Sugawara, K. Sakaguchi, Y. Mizushina, Biochem. Pharmacol. 65 (2003) 259.

[21] A. Bruno, C. Rossi, G. Marcolongo, A. Di Lena, A. Venzo, C.P. Berrie, D. Corda, Eur. J. Pharmacol. 524 (2005) 159. 
[22] M. Lenti , C. Gentili , A. Pianezzi, G. Marcolongo, A. Lalli, R. Cancedda, F.D. Cancedda, Nat. Prod. Res. 23 (2009) 754.

[23] K. Matsubara, H. Matsumoto, Y. Mizushina, M. Mori, N. Nakajima, M. Fuchigami, H. Yoshida, T. Hada, Oncol. Rep. 14 (2005) 157.

[24] N. Maeda, Y. Kokai, S. Ohtani, H. Sahara, T. Hada, C. Ishimaru, I. Kuriyama, Y. Yonezawa, H. Iijima, H. Yoshida, N. Sato, Y. Mizushina, Nutr. Cancer. 57 (2007) 216. [25] N. Maeda, Y. Kokai, S. Ohtani, H. Sahara, Y. Kumamoto-Yonezawa, T. Hada, C. Ishimaru, I. Kuriyama, Y. Yonezawa, H. Iijima, , N. Sato, H. Yoshida, Y. Mizushina, Lipids 43 (2008) 741.

[26] I. Kuriyama, K. Musumi, Y. Yonezawa, M. Takemura, N. Maeda, H. Iijima, T. Hada, H. Yoshida, Y. Mizushina, J Nutr. Biochem. 16 (2005) 594.

[27] C. Bottier, J. Géan, F. Artzner, B. Desbat, M. Pézolet, A. Renault, D. Marion, V. Vié, Biochim. Biophys. Acta 1768 (2007) 1526.

[28] B. Gzyl-Malcher, M. Filek, K.Makyła, M. Paluch, Chem. Phys. Lipids 155 (2008) 24.

[29] M. Tomoaia-Cotisel, J.Zsakó, E. Chifu, P. J. Quinn, Chem. Phys. Lipids 34 (1983) 55.

[30] V. Castro, S.V. Dvinskikh, G. Widmalm, D. Sandström, A. Maliniak, Biochim. Biophys. Acta 1768 (2007) 2432.

[31] M. Tomoaia-Cotisel, J. Zsako, E. Chifu, P.J. Quinn, Chem. Phys. Lipids 50 (1989) 127.

[32] A. A. Foley, A. P.R. Brain, P. J. Quinn, J. L. Harwood, Biochim. Biophys. Acta 939 (1988) 430.

[33] P. J. Quinn and L. J. Lis, Biochem. Soc. Trans. 14 (1986) 650.

[34] A.R. Mansourian, A.P.R. Brain P. J. Quinn, Biochem. Soc. Trans. 14 (1986) 738.

[35] A. Sen, W. P. Williams, A. P. R. Brain, M. J. Dickens, P. J. Quinn, Nature 293 (1981) 488.

[36] F. D. Gunstone, J.L. Harwood, A. J. Dijkstra, The Lipid Handbook, CRC Press, 2007 p. 123.

[37] M.I. Gurr, J.L. Harwood, K.N. Frayn, Lipid Biochemistry, John Wiley and Sons, 2002 p. 219.

[38] C. Bottier, J. Géan, B. Desbat, A. Renault, D. Marion, V. Vié, Langmuir 24 (2008) 10901.

[39] J.T.Davies, E.K.Rideal, Interfacial Phenomena, Academic Press Inc., NewYork, 1963 p. 265.

[40] P. Vitovič, D.P. Nikolelis, T. Hianik, Biochim. Biophys. Acta 1758 (2006) 1852. 
[41] J. Torrent-Burgues, M. Pla, L. Escriche, J. Casabo, A. Errachid, F. Sanz, J. Colloid Interf. Sci. 301 (2006) 585.

[42] G. Oncins, J. Torrent-Burgues, F. Sanz, Trib. Lett. 21 (2006) 175.

[43] O. Domenech, J. Torrent-Burgués, S. Merino, F.Sanz, M.T. Montero, J HernandezBorrell, Colloids Surf. B 41 (2005) 233.

[44] T.-H. Chou, I.-M. Chu, C.-H. Chang, Colloids Surf. B 25 (2002) 147.

[45] G.L.Gaines Jr., Insoluble Monolayers at Liquid-Gas Interfaces, John Wiley \& Sons, New York, 1966.

[46] M. Jemioła-Rzemińska, B. Myśliwa-Kurdziel, K. Strzałka, Chem. Phys. Lipids 114 (2002) 169.

[47] M. Filek, B. Gzyl, P. Laggner, M. Kriechbaum, J. Plant Physiol. 162 (2005) 245.

[48] Y. Roche, P. Peretti, S. Bernard, Biochim. Biophys. Acta 1758 (2006) 468.

[49] J. Sanchez, A.Badia, Thin Solid Films 440 (2003) 223.

[50] L.Zhao, S.-S. Feng, J. Colloid Interf. Sci. 274 (2004) 55.

[51] D. Guay, R.M. Leblanc, Langmuir 3 (1987) 575.

[52] Lipidmaps ID: LMGL05010022 


\section{Captions for figures}

Scheme 1. A) Plastoquinone-9, B) Ubiquinone-10, C) Monogalactosyldiacylglycerol

Figure 1. $\pi$-A isotherms for MGDG, UQ and MGDG:UQ mixtures at $21 \pm 0.5^{\circ} \mathrm{C}$. Inset:

Inverse of the compressibility modulus vs. surface pressure for MGDG, UQ and MGDG:UQ mixture film isotherms.

Figure 2A. Plot of the Mean area per molecule vs. the molar fraction for MGDG, UQ and MGDG:UQ mixtures at several surface pressures below UQ collapse. $\pi=2(\boldsymbol{\bullet}), \pi=4(\bullet), \pi=$ $6(\Delta), \pi=8(\diamond), \pi=10(\star) \mathrm{mN} \cdot \mathrm{m}^{-1}$. Discontinuous straight lines represent the ideal behaviour for each surface pressure.

Figure 2B. Plot of the Mean area per molecule vs. the molar fraction for MGDG, UQ and MGDG:UQ mixtures at several surface pressures higher than UQ collapse. $\pi=15(\boldsymbol{\square}), \pi=25$ $(\bullet), \pi=32(\Delta), \pi=40(\bullet), \pi=48(\star) \mathrm{mN} \cdot \mathrm{m}^{-1}$. Discontinuous straight lines represent the ideal behaviour for each surface pressure.

Figure 3A. Plot of the excess energy vs. the molar fraction for MGDG, UQ and MGDG:UQ mixtures at several surface pressures below the UQ collapse $\pi=2(\boldsymbol{\bullet}), \pi=4(\bullet), \pi=6(\boldsymbol{\Delta}), \pi$ $=8(\diamond), \pi=10(\star) \mathrm{mN} \cdot \mathrm{m}^{-1}$.

Figure 3B. Plot of the mixing energy vs. the molar fraction for MGDG, UQ and MGDG:UQ mixtures at several surface pressures below the UQ collapse $\pi=2(\boldsymbol{\bullet}), \pi=4(\bullet), \pi=6(\boldsymbol{\Delta}), \pi$ $=8(\diamond), \pi=10(\star) \mathrm{mN} \cdot \mathrm{m}^{-1}$.

Figure 4. A) Lift-off zone zoom of the MGDG:UQ 10:1 $\pi$-A isotherm. Inset: Inverse of the compressibility modulus vs. surface pressure. B) BAM image of the monolayer MGDG:UQ $10: 1$ at $21^{\circ} \mathrm{C}$ and at the lift-off zone $\left(\pi=0.25 \mathrm{mN} \cdot \mathrm{m}^{-1}\right.$ and $\mathrm{A}=72 \AA^{2} \cdot$ molecule $\left.^{-1}\right)$.

Figure 5. BAM images of a MGDG:UQ 10:1 mixture monolayer at $21^{\circ} \mathrm{C}$ and at selected phase states. A) $\pi=4.7 \mathrm{mN} \cdot \mathrm{m}^{-1}$ and $\mathrm{A}=61 \AA^{2} \cdot \mathrm{molecule}^{-1}$, B) $\pi=13.9 \mathrm{mN} \cdot \mathrm{m}^{-1}$ and $\mathrm{A}=53$ $\AA^{2} \cdot$ molecule $^{-1}$, C) $\pi=40.0 \mathrm{mN} \cdot \mathrm{m}^{-1}$ and $\mathrm{A}=44 \AA^{2} \cdot$ molecule $^{-1}$. 
Figure 6. AFM images $(10 \mu \mathrm{m} \times 10 \mu \mathrm{m})$ of $\mathrm{LB}$ films transferred on mica for MGDG at $21^{\circ} \mathrm{C}$ and for $\pi=$ A) 6, B) 15, C) 25 and D) $40 \mathrm{mN} \cdot \mathrm{m}^{-1}$.

Figure 7. AFM image $(5 \mu \mathrm{m} \times 5 \mu \mathrm{m})$ of pure UQ at $\pi=6 \mathrm{mN} \cdot \mathrm{m}^{-1}$ and $21^{\circ} \mathrm{C}$.

Figure 8. AFM images $(10 \mu \mathrm{m} \times 10 \mu \mathrm{m})$ of LB films transferred on mica at $21^{\circ} \mathrm{C}$ and $\pi=6$ $\mathrm{mN} \cdot \mathrm{m}^{-1}$ for A) pure MGDG, B) MGDG:UQ 20:1, C) MGDG:UQ 10:1, D) MGDG:UQ 5:1.

Figure 9. AFM images (10 $\mu \mathrm{m} \times 10 \mu \mathrm{m})$ of MGDG:UQ 5:1 LB films transferred on mica at $21^{\circ} \mathrm{C}$ for several surface pressures A) $\left.\left.\left.\pi=6 \mathrm{mN} \cdot \mathrm{m}^{-1} \mathrm{~B}\right) \pi=15 \mathrm{mN} \cdot \mathrm{m}^{-1} \mathrm{C}\right) \pi=25 \mathrm{mN} \cdot \mathrm{m}^{-1} \mathrm{D}\right) \pi$ $=40 \mathrm{mN} \cdot \mathrm{m}^{-1}$. 